\title{
Mantle cooling causes more reducing volcanic gases and gradual reduction of the atmosphere
}

\author{
S. Kadoya ${ }^{\text {**, D.C. Catling}{ }^{1} \text {, R.W. Nicklas }}{ }^{3}$, I.S. Puchtel ${ }^{2}$, A.D. Anbar ${ }^{4}$
}

Abstract

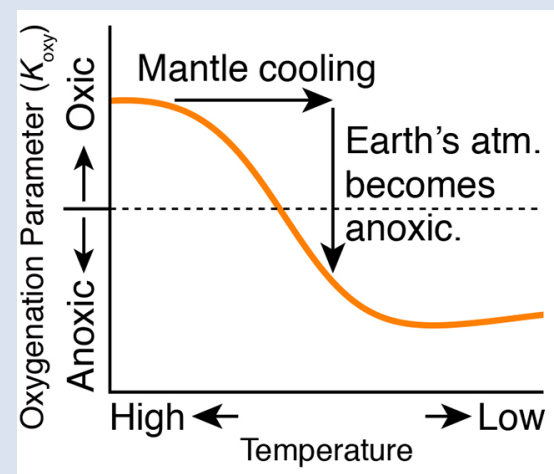

The early atmosphere contained negligible $\mathrm{O}_{2}$ until the Great Oxidation Event (GOE) around $2.4 \mathrm{Ga}$, but evidence suggests that production of photosynthetic $\mathrm{O}_{2}$ began hundreds of millions of years earlier. Thus, an ongoing debate concerns the trigger of the GOE. One possibility is that volcanic gases became more oxidising over time. Secular cooling of the mantle affects thermodynamic equilibria and also changes the proportions of reduced and oxidised volcanic gases. Here, we examine the consequences of mantle cooling for the evolution of Earth's atmospheric redox state. Contrary to some previous hypotheses, we show that as the mantle cools, volcanic emissions contain a greater proportion of reducing gases, which produces a more reducing atmosphere. However, the atmosphere became more oxic. Therefore, the redox consequences of other processes, such as secular oxidation of the mantle and/or hydrogen escape to space, must have dominated over that of mantle cooling in shaping the redox evolution of Earth's atmosphere.

Received 11 October 2019 | Accepted 12 February 2020 | Published 16 March 2020

\section{Introduction}

The partial pressure of Archean atmospheric $\mathrm{O}_{2}$ was $<0.2 \times$ $10^{-6}$ bar and rose during the Great Oxidation Event (GOE), between $2.4 \mathrm{Ga}$ and $2.1 \mathrm{Ga}$, as indicated by the disappearance of mass independent sulfur isotope fractionation in sedimentary rocks (Farquhar et al., 2000; Pavlov and Kasting, 2002; Zahnle et al., 2006). However, chromium, iron, and molybdenum isotope data suggest the presence of $\mathrm{O}_{2}$ in the marine photic zone (oxygen oases) as early as $\sim 3 \mathrm{Ga}$ (Planavsky et al., 2014; Satkoski et al., 2015), and evidence exists for mild oxygenation from these and other proxies at $2.5 \mathrm{Ga}$ (Ostrander et al., 2019 and references therein). Evidence for free $\mathrm{O}_{2}$ before the GOE is also consistent with phylogenetic inferences that oxygenic photosynthesis evolved by the mid to late Archean (Schirrmeister et al., 2015; Magnabosco et al., 2018); earlier, anoxygenic photosynthesis would have been present (Sleep, 2018).

The reason for the apparent time lag between the advent of oxygenic photosynthesis and the GOE is debated (Catling et al., 2001; Holland, 2002; Kump and Barley, 2007; Holland, 2009; Gaillard et al., 2011; Kasting, 2013; Ciborowski and Kerr, 2016; Lee et al., 2016; Brounce et al., 2017; Duncan and Dasgupta, 2017; Moussallam et al., 2019). One possibility is that if ancient volcanic gases were sufficiently reducing, they would have overwhelmed $\mathrm{O}_{2}$ production fluxes, limiting $\mathrm{O}_{2}$ to trace levels. If volcanic gases became gradually more oxidised, atmospheric $\mathrm{O}_{2}$ would accumulate rapidly at a tipping point when the reducing volcanic gas flux fell below the $\mathrm{O}_{2}$ production flux (Holland, 2002; Claire et al., 2006).

Several hypotheses account for gradual oxidation of volcanic gases: the oxidation of the mantle as a consequence of hydrogen escape to space (Kasting et al., 1993); a decrease in volcanic degassing pressure associated with an increase in subaerial volcanoes (Kump and Barley, 2007; Gaillard et al., 2011) though this hypothesis is contradicted by Brounce et al. (2017); increasing $\mathrm{CO}_{2}$ and/or $\mathrm{SO}_{2}$ degassing due to increased subduction of carbonate and sulfate sediments (Holland, 2002, 2009) or plume magmatism (Ciborowski and Kerr, 2016); and/ or an increase in recycling of organic material (Duncan and Dasgupta, 2017).

Recently, Moussallam et al. (2019) suggested that a decrease in volcanic emission temperature, which they defined as that of the fumarole where gases enter the air, caused volcanic gases to become more oxidised. They argued that the secular cooling of the planetary interior caused a decrease in emission temperatures, oxidation of volcanic gases, and the GOE. Specifically, they considered the cooling of a parcel of gas in a volcanic vent as a closed system separated from a melt.

\footnotetext{
1. Department of Earth and Space Sciences / cross-campus Astrobiology Program, University of Washington, Box 351310, Seattle, WA 98195-1310, USA

2. Department of Geology, University of Maryland, College Park, MD 20742, USA

3. Geoscience Research Division, Scripps Institution of Oceanography, La Jolla, CA 92093, USA

4. School of Earth and Space Exploration and School of Molecular Sciences, Arizona State University, Tempe, AZ 85287, USA

Corresponding author (email: shintaro.kadoya@gmail.com)
} 
Here, we examine how cooling affected volcanic gas buffered by a surrounding melt and gases in a subsequent closed system. We analyse the effect of inferred changes in the proportions of oxidised and reduced volcanic gases on the redox state of the atmosphere.

\section{Model}

We begin by describing our model briefly. Supplementary Information Section S-1 contains additional details. We assume that volcanic gas consists of $\mathrm{H}_{2} \mathrm{O}, \mathrm{H}_{2}, \mathrm{CO}_{2}, \mathrm{CO}, \mathrm{CH}_{4}, \mathrm{SO}_{2}$, and $\mathrm{H}_{2} \mathrm{~S}$ in thermodynamic equilibrium at a total pressure of 5 bar, assuming a subaerial volcanic eruption (Holland, 1984; p. 47). Section S-8 discusses how the redox state of volcanic gases changes outside of this nominal pressure value. Partial pressures of the gas species are calculated using mass conservation of hydrogen, carbon, and sulfur, and relevant thermodynamic equilibria (see also Section S-1.1).

We model two end members of the redox state of the gas mixture. This redox state corresponds to the amount of oxygen within the gas mixture, which is described in our two cases as follows. In one case, the "buffered system", the gas interacts with surrounding melt and rocks. Oxygen exchanges with the melt such that $\mathrm{O}_{2}$ fugacity is fixed at a given temperature and pressure. For the other case, the "closed system", we assume that the gas and its reactions are isolated from the melt, and since no constituents are supplied or released, we conserve mass for oxygen, hydrogen, carbon, and sulfur (Supplementary Information Eq. S-12; see also Eq. S-6, S-7 and S-8).

We evaluate the oxygenation effect of volcanic gas using an oxygenation parameter, $K_{\text {oxy, }}$ introduced in previous studies (Catling and Claire, 2005; Claire et al., 2006; Kasting, 2013) This parameter is the ratio of the source flux of $\mathrm{O}_{2}\left(F_{\text {source }}\right)$ to the kinetically rapid sink flux of $\mathrm{O}_{2}\left(F_{\text {sink }}\right)$ :

$$
K_{\text {oxy }} \equiv \frac{F_{\text {source }}}{F_{\text {sink }}}
$$

Here, $F_{\text {sink }}$ corresponds to degassing of reductive, i.e. oxidisable, volcanic gases, which can include an excess of reductants beyond that which reacts with $\mathrm{O}_{2}$.

By construction, $F_{\text {source }}$ and $F_{\text {sink }}$ are not meant to balance each other: they omit fluxes that depend on atmospheric redox state, such as hydrogen escape to space in $F_{\text {source }}$ and oxidative weathering, e.g., oxidation of $\mathrm{Fe}^{2+}$ to $\mathrm{Fe}^{3+}$, in $F_{\text {sink }}$ (Catling and Claire, 2005; Kasting, 2013). When $K_{\text {oxy }}<1, \mathrm{O}_{2}$ sinks exceed $\mathrm{O}_{2}$ sources and excess $\mathrm{H}_{2}$ accumulates until balanced by escape to space. When $\mathrm{K}_{\text {oxy }}>1, \mathrm{O}_{2}$ sources exceed $\mathrm{O}_{2}$ sinks and $\mathrm{O}_{2}$ accumulates until balanced by oxidative weathering. The evolution of $K_{\text {oxy }}$ in a box model coupled to photochemistry shows how atmospheric oxygenation occurs when $K_{\text {oxy }}$ reaches unity (Claire et al., 2006).

We assume that oxygenic photosynthesis is present because we are evaluating $\mathrm{O}_{2}$ build up. We consider $\mathrm{H}_{2} \mathrm{O}$, $\mathrm{CO}_{2}$, and $\mathrm{SO}_{2}$ to be redox neutral, while $\mathrm{H}_{2}, \mathrm{CO}, \mathrm{CH}_{4}$, and $\mathrm{H}_{2} \mathrm{~S}$ fluxes consume $\mathrm{O}_{2}$ in atmospheric photochemistry. The burial of organic matter and pyrite $\left(\mathrm{FeS}_{2}\right)$ are $\mathrm{O}_{2}$ source fluxes. Considering the stoichiometry of $\mathrm{O}_{2}$ consumption and production, we rewrite Eq. 1 as follows (derived in Section S-1):

$$
K_{\text {oxy }} \equiv \frac{4 f_{\text {org }} \times\left(p \mathrm{CO}_{2}+p \mathrm{CO}+p \mathrm{CH}_{4}\right)+5 p \mathrm{SO}_{2}}{2 p \mathrm{H}_{2}+2 p \mathrm{CO}+8 p \mathrm{CH}_{4}+p \mathrm{H}_{2} \mathrm{~S}} \text { Eq. } 2
$$

Here, $f_{\text {org }}$ represents the fraction of carbon buried as sedimentary organic carbon. Although $f_{\text {org }}$ has changed with time, for a nominal case, we set $f_{\text {org }}$ to $20 \%$, which is a rough average over geologic time (Krissansen-Totton et al., 2015). Section S-7 discusses the dependence of $K_{\text {oxy }}$ on variations of $f_{\text {org }}$. The mechanism that sets $f_{\text {org }}$ is beyond our scope. However, $f_{\text {org }}$ might be controlled by divalent cation fluxes that modulate the carbonate burial flux, which complements the organic burial flux (Sleep, 2005).

\section{Results and Discussion}

The degassing process has two stages. Firstly, a gas bubble emerges from melt. The oxygen fugacity of this gas mixture is buffered by the surrounding melt since gases react with the melt. So, this stage corresponds to the buffered system case. Secondly, the bubble ascends within the melt, and the gas temperature adiabatically decreases with decompression (Oppenheimer et al., 2018). In this stage, gases react with each other within the closed system bubble. Hereafter, we explain the redox speciation of volcanic gases during each stage.

First, we consider the oxidation state of global volcanic gas emissions for the buffered system. We define the redox state as the difference of logarithm of $f_{\mathrm{O} 2}$ from that of the Quartz-Fayalite-Magnetite (QFM) buffer: $\triangle \mathrm{QFM}=\log _{10} f_{\mathrm{O} 2}$ $-\log _{10} f_{\mathrm{O} 2, \mathrm{qfm}}$. Also, we consider 4 different redox states of the surrounding melt (and rocks), and we assume that the redox state of the surroundings in each case is constant and independent of temperature. Since we consider cooling from $2000 \mathrm{~K}$, we denote the oxidation state of the melt as $\Delta \mathrm{QFM}_{2000}$. The choice of the initial temperature is arbitrary and does not affect our conclusions.

The $\triangle Q F M$ of the gas is equal to the $\triangle Q F M$ of the surroundings and is temperature independent (Fig. 1a) because of buffering by the surrounding melt and rocks. However, since the reference $f_{\mathrm{O} 2}$ of the QFM buffer decreases with cooling (Fig. S-1a), the absolute $f_{\mathrm{O} 2}$ value of gas and melt decreases with cooling even though their $\triangle Q F M$ values are constant.

The corresponding $K_{\text {oxy }}$ value tells us whether atmospheric oxygenation occurs. $K_{\text {oxy }}$ depends on gas composition (Eq. 2), which depends on the equilibrium constant of each reaction in addition to $f_{\mathrm{O} 2}$. Equilibrium constants also depend on temperature (Fig. S-1b). Consequently, cooling causes oxidation of $\mathrm{CO}$ to $\mathrm{CO}_{2}$ and reduction of $\mathrm{SO}_{2}$ to $\mathrm{H}_{2} \mathrm{~S}$ (Fig. S-1c), even though the redox buffer relative to QFM is constant (see also Section S-2). The net effect of these opposing changes is a step-like decrease in $K_{\text {oxy }}$ with cooling, as shown in Figure $1 b$. In particular, for the case with $\triangle \mathrm{QFM}=-0.5$, cooling decreases $K_{\text {oxy }}$ from $>1$ to $<1$ (dashed line, Fig. $1 b$ ), which would cause the atmosphere to flip from oxic to reducing.

Now consider a parcel of volcanic gases separated from a melt, e.g., in a volcanic vent. For this closed system gas composition, we calculate an equivalent $\triangle \mathrm{QFM}$ using the mole ratio of gas species, such as $\mathrm{H}_{2} / \mathrm{H}_{2} \mathrm{O}$ (Section $\mathrm{S}-4$ ). Cooling changes the $\triangle$ QFM (Fig. 2a), unlike in the buffered system (Fig. 1a). In particular, for relatively oxidised cases (i.e. $\triangle \mathrm{QFM}_{2000}=0$ and -0.5), $\triangle$ QFM increases with cooling (solid and dashed lines in Fig. 2a), consistent with the results of Moussallam et al. (2019). However, for relatively reduced cases (i.e. $\triangle \mathrm{QFM}_{2000}=$ -1 and -1.5), the change in $\triangle \mathrm{QFM}$ is moderate (dash-dot and dashed lines in Fig. 2a). The increase in $\triangle$ QFM with cooling in the closed system occurs because reduction of $\mathrm{SO}_{2}$ to $\mathrm{H}_{2} \mathrm{~S}$ is accompanied by oxidation of $\mathrm{H}_{2}$ to $\mathrm{H}_{2} \mathrm{O}$ by redox conservation (Section S-3). Consequently, the ratio $p \mathrm{H}_{2} / p \mathrm{H}_{2} \mathrm{O}$ declines, producing a relative increase in $f_{\mathrm{O} 2}$ (see Sections S-3 and S-4).

$K_{\text {oxy }}$ also changes with cooling of the closed system gas (Fig. 2b). However, within the closed system, reduction of one gas is accompanied by oxidation of another gas. Consequently, temperature dependent reactions within a closed system gas mixture do not change the overall sink of $\mathrm{O}_{2}$ in the gas mixture, contrary to the conclusions of Moussallam et al. (2019). 


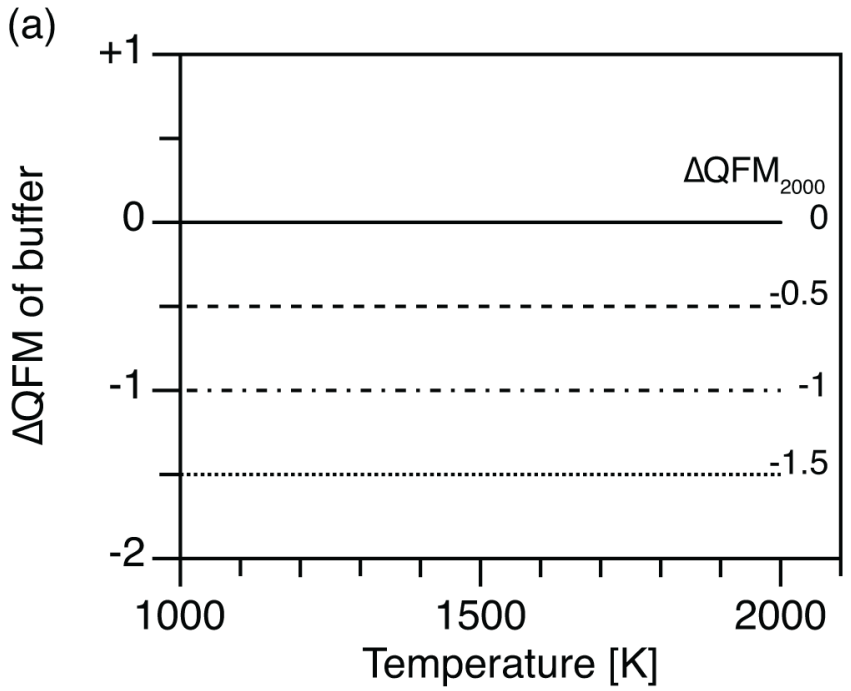

(b)

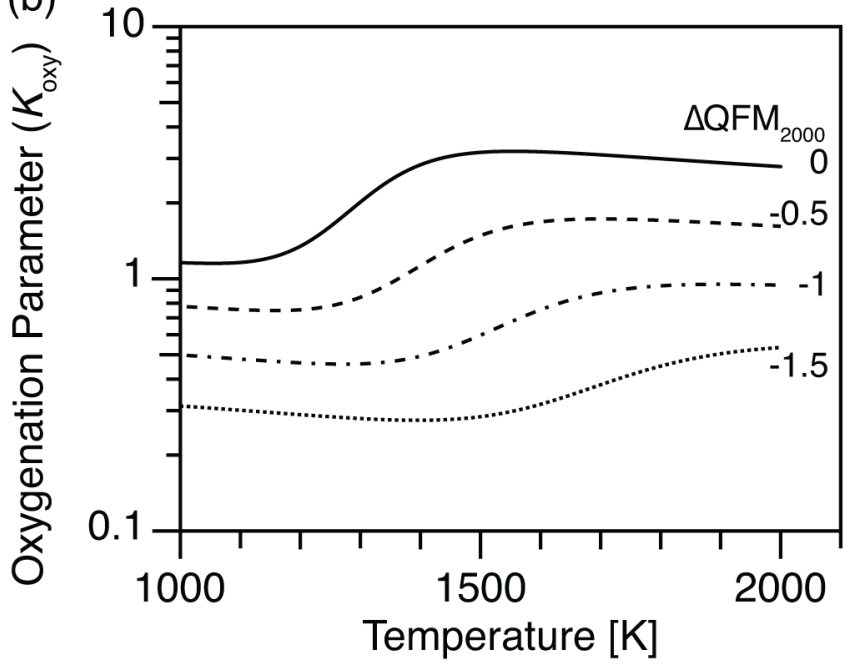

Figure 1 (a) Oxidation state ( $\triangle \mathrm{QFM}$ ) buffering volcanic gas composition, and (b) oxygenation parameter $\left(K_{\text {oxy }}\right)$, as a function of temperature. Here, we assume a system where gases are redox buffered by the surrounding melt and rocks. $\triangle \mathrm{QFM}_{2000}$ represents the oxidation state at $2000 \mathrm{~K}$. By definition, $\triangle \mathrm{QFM}$ is independent of temperature and equal to $\triangle \mathrm{QFM}_{2000}$ in (a) whereas cooling tends to decrease $K_{\text {oxy }}$ in (b).

For example, consider a mixture initially containing $1 \mathrm{~mol}$ of $\mathrm{SO}_{2}$ and $3 \mathrm{~mol}$ of $\mathrm{H}_{2}$, where all $\mathrm{SO}_{2}$ is reduced, $\mathrm{SO}_{2}+3 \mathrm{H}_{2} \rightarrow \mathrm{H}_{2} \mathrm{~S}+2 \mathrm{H}_{2} \mathrm{O}$ (see also Section S-3). The moles of $\mathrm{O}_{2}$ that can be consumed by the gas mixture do not change. Reduction of $1 \mathrm{~mol} \mathrm{SO}$ accompanied by oxidation of $3 \mathrm{~mol}$ $\mathrm{H}_{2}$ decreases the overall sink of $\mathrm{O}_{2}$ by $0.25 \mathrm{~mol} \mathrm{O}_{2}$ but the production of $1 \mathrm{~mol} \mathrm{H}_{2} \mathrm{~S}$ compensates.

A subtlety is that although the $\mathrm{O}_{2}$ sink cannot change, $K_{\text {oxy }}$ shifts because $K_{\text {oxy }}$ also accounts for global $\mathrm{O}_{2}$ sources from converted volcanic gases. In our 'toy' example, $1 \mathrm{~mol}$ $\mathrm{SO}_{2}$ corresponds to a $1.25 \mathrm{~mol} \mathrm{O}_{2}$ source (see Section S-1.2), while $3 \mathrm{~mol}$ of $\mathrm{H}_{2}$ and $1 \mathrm{~mol}$ of $\mathrm{H}_{2} \mathrm{~S}$ correspond to $1.5 \mathrm{~mol} \mathrm{O}_{2}$ and $0.25 \mathrm{~mol} \mathrm{O}_{2}$ sinks, respectively. Hence, the initial $K_{\text {oxy }}$ is $1.25 / 1.5=5 / 6$, but after reactions, $K_{\text {oxy }}$ becomes $0 / 0.25=0$. Here, the expected reduction of $\mathrm{SO}_{2}$ to pyrite in the global environment (Eq. S-18) is the source of $\mathrm{O}_{2}$ that changes $K_{\text {oxy. }}$. The important point is that an initial $K_{\text {oxy }}$ of $<1$ remains less than unity.

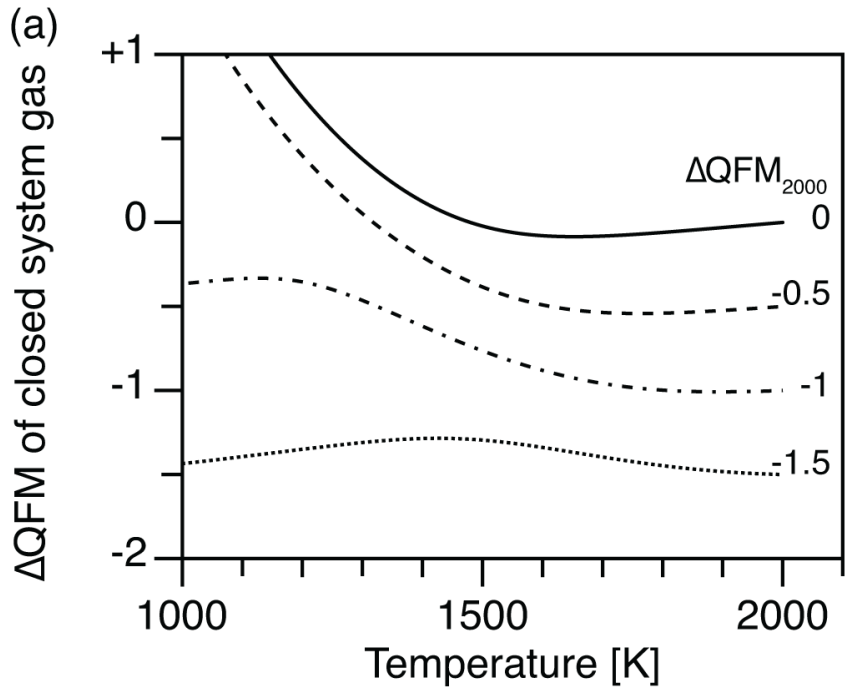

(b)

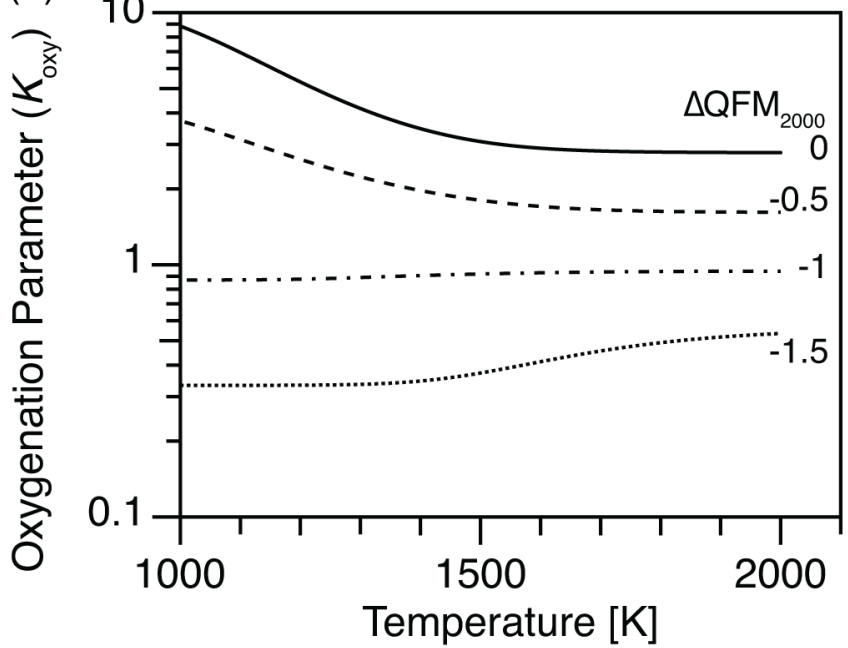

Figure 2 (a) Oxidation state ( $\triangle \mathrm{QFM})$, and (b) oxygenation parameter $\left(K_{\text {oxy }}\right)$, as a function of temperature. Here, we assume a closed system of gases, and the $\triangle \mathrm{QFM}$ of the gases at $2000 \mathrm{~K}$ is denoted as $\triangle Q F M_{2000}$. Cooling changes $\triangle Q F M$ unlike the melt buffered case (Fig. 1a) and changes $K_{\text {oxy }}$. However, an initial $K_{\text {oxy }}$ that exceeds unity remains $>1$ with cooling, and an initial $K_{\text {oxy }}$ that is less than unity remains $<1$.

Consider again Figure 2. Temperature dependent gas reactions within a closed system do not change the overall sink of $\mathrm{O}_{2}$ in the gas mixture. For relatively oxidised cases $\left(\triangle \mathrm{QFM}_{2000}=0\right.$ and -0.5$)$, cooling increases $K_{\text {oxy }}$ (solid and dashed lines in Fig. 2b). However, for relatively reduced cases $\left(\triangle \mathrm{QFM}_{2000}=-1\right.$ and -1.5$)$, cooling decreases $K_{\text {oxy }}$ (dash-dot and dotted lines in Fig. $2 b$ ). In summary, an initial $\mathrm{K}_{\text {oxy }}$ of $>1$ remains larger than unity with cooling, while an initial $\mathrm{K}_{\text {oxy }}$ of $<1$ stays less than unity (Fig. $2 b$ ).

Therefore, reactions under a melt buffer system change the capacity of the gas to consume $\mathrm{O}_{2}$ and affect atmospheric oxygenation while reactions within the closed system cannot. So, the oxygenation effect of volcanic degassing depends on interactions with the melt.

The Earth's interior likely cooled with time (Bickle, 1982; Nisbet et al., 1993; Herzberg et al., 2010; Aulbach and Arndt, 2019). However, even if the upper mantle's oxidation state was constant (e.g., $\triangle \mathrm{QFM}=-0.5)$, its cooling would decrease $K_{\text {oxy }}$ 
and even reduce the atmosphere (Fig. 1b). Thus, processes that dominate over such a $K_{\text {oxy }}$ decrease are required to explain the GOE.

The trigger for the GOE is debated (Kasting et al., 1993; Catling et al., 2001; Holland, 2002; Gaillard et al., 2011; Moussallam et al., 2019). Proposed secular oxidation of the upper mantle caused by hydrogen escape (Kasting et al., 1993) has been dismissed for about two decades because evidence appeared to show a constant oxidation state of the upper mantle (Canil, 1997; Delano, 2001; Canil, 2002; Lee et al., 2005). However, two recent studies suggest that the upper mantle $\triangle$ QFM increased by $\sim 1.5 \log _{10}$ units since the early Archean (Aulbach and Stagno, 2016; Nicklas et al., 2019). Such oxidation would cause $K_{\mathrm{oxy}}$ to increase and so possibly triggered the GOE. Regardless, we have shown that if mantle $\triangle \mathrm{QFM}$ does not increase, mantle cooling actually makes the atmosphere more reducing, contrary to previous claims that mantle cooling would trigger the GOE (Moussallam et al., 2019).

\section{Conclusions}

We examined the effects of Earth's secular cooling and volcanic gases on oxygenation of the atmosphere using an oxygenation parameter, $K_{\text {oxy }}$ that is less than unity for an anoxic atmosphere and exceeds unity for an oxic atmosphere (Catling and Claire, 2005; Kasting, 2013). Low temperature favours $\mathrm{H}_{2} \mathrm{~S}$ more than $\mathrm{SO}_{2}$ because both equilibria constants and the absolute $\mathrm{O}_{2}$ fugacity of the QFM buffer depend on temperature. Hence, for a buffered system, cooling increases the $p \mathrm{H}_{2} \mathrm{~S} / p \mathrm{SO}_{2}$ ratio in volcanic gases and decreases $K_{\text {oxy }}$. For a closed system of gases in a vent that is not melt buffered, cooling also increases the $p \mathrm{H}_{2} \mathrm{~S} / p \mathrm{SO}_{2}$ ratio but this is counteracted by a decrease in $p \mathrm{H}_{2} / p \mathrm{H}_{2} \mathrm{O}$. Hence, cooling of a closed system parcel of gas does not change the overall capacity of the volcanic gases to consume $\mathrm{O}_{2}$.

We conclude that the long term cooling of the mantle induced changes in volcanic gas composition that reduced the atmosphere. However, other processes dominated because the atmosphere oxygenated with time. Possibilities include secular oxidation of the mantle (Aulbach and Stagno, 2016; Nicklas et al., 2019) and/or growth in the $\mathrm{O}_{2}$ source flux due to higher rates of organic carbon burial (relative to oxidant burial) (Krissansen-Totton et al., 2015).

\section{Acknowledgements}

Funding support came from NSF Frontiers in Earth System Dynamics award No. 1338810.

Editor: Ambre Luguet

\section{Additional Information}

Supplementary Information accompanies this letter at http:// www.geochemicalperspectivesletters.org/article2009.

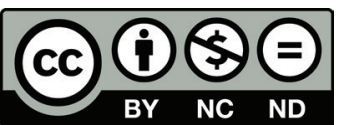

This work is distributed under the Creative Commons Attribution Non-Commercial No-Derivatives 4.0 License, which permits unrestricted distribution provided the original author and source are credited. The material may not be adapted (remixed, transformed or built upon) or used for commercial purposes without written permission from the author. Additional information is available at http://www.geochemicalperspectivesletters.org/ copyright-and-permissions.
Cite this letter as: Kadoya, S., Catling, D.C., Nicklas, R.W., Puchtel, I.S., Anbar, A.D. (2020) Mantle cooling causes more reducing volcanic gases and gradual reduction of the atmosphere. Geochem. Persp. Let. 13, 25-29.

\section{References}

Aulbach, S., ARndt, N.T. (2019) Eclogites as palaeodynamic archives: Evidence for warm (not hot) and depleted (but heterogeneous) Archaean ambient mantle. Earth and Planetary Science Letters 505, 162-172.

Aulbach, S., Stagno, V. (2016) Evidence for a reducing Archean ambient mantle and its effects on the carbon cycle. Geology 44, 751-754.

BICKLE, M.J. (1982) The magnesian contents of komatiitic liquids. In: Arndt, N.T., Nisbet, E.G. (Eds.), Komatiites. Allen and Unqin, London, 477-494.

Brounce, M., Stolper, E., EILER, J. (2017) Redox variations in Mauna Kea lavas, the oxygen fugacity of the Hawaiian plume, and the role of volcanic gases in Earth's oxygenation. Proceedings of the National Academy of Sciences of the United States of America 114, 8997-9002.

CANIL, D. (1997) Vanadium partitioning and the oxidation state of Archaean komatiite magmas. Nature 389, 842-845.

CANIL, D. (2002) Vanadium in peridotites, mantle redox and tectonic environments: Archean to present. Earth and Planetary Science Letters 195, 75-90.

Catling, D.C., Claire, M.W. (2005) How Earth's atmosphere evolved to an oxic state: A status report. Earth and Planetary Science Letters 237, 1-20.

Catling, D.C., Zahnle, K.J., McKay, C.P. (2001) Biogenic methane, hydrogen escape, and the irreversible oxidation of early Earth. Science 293, 839-843.

CiborowsKi, T.J.R., KerR, A.C. (2016) Did mantle plume magmatism help trigger the Great Oxidation Event? Lithos 246, 128-133.

Claire, M.W., Catling, D.C., Zahnle, K.J. (2006) Biogeochemical modelling of the rise in atmospheric oxygen. Geobiology 4, 239-269.

Delano, J.W. (2001) Redox history of the Earth's interior since similar to 3900 Ma: Implications for prebiotic molecules. Origins of Life and Evolution of the Biosphere 31, 311-341.

Duncan, M.S., DAsGupta, R. (2017) Rise of Earth's atmospheric oxygen controlled by efficient subduction of organic carbon. Nature Geoscience 10, 387-+

FARQUhar, J., BAO, H.M., ThIEMEnS, M. (2000) Atmospheric influence of Earth's earliest sulfur cycle. Science 289, 756-758.

Gaillard, F., Scaillet, B., ARndt, N.T. (2011) Atmospheric oxygenation caused by a change in volcanic degassing pressure. Nature 478 , 229-U112.

Herzberg, C., Condie, K., Korenaga, J. (2010) Thermal history of the Earth and its petrological expression. Earth and Planetary Science Letters 292, 79-88.

Holland, H.D. (1984) The chemical evolution of the atmosphere and oceans. Princeton University Press, Princeton, N.J.

HolLAND, H.D. (2002) Volcanic gases, black smokers, and the Great Oxidation Event. Geochimica et Cosmochimica Acta 66, 3811-3826.

Holland, H.D. (2009) Why the atmosphere became oxygenated: A proposal. Geochimica et Cosmochimica Acta 73, 5241-5255.

KAsting, J.F. (2013) What caused the rise of atmospheric O-2? Chemical Geology 362, 13-25.

Kasting, J.F., EgGler, D.H., RAEburN, S.P. (1993) Mantle Redox Evolution and the Oxidation-State of the Archean Atmosphere. Journal of Geology 101, 245-257.

Krissansen-TotTon, J., Buick, R., CATLing, D.C. (2015) A Statistical Analysis of the Carbon Isotope Record from the Archean to Phanerozoic and Implications for the Rise of Oxygen. American Journal of Science 315, 275-316.

KUMP, L.R., BARLEY, M.E. (2007) Increased subaerial volcanism and the rise of atmospheric oxygen 2.5 billion years ago. Nature 448, 1033-1036.

Lee, C.T.A., LeEman, W.P., CAnil, D., Li, Z.X.A. (2005) Similar V/Sc systematics in MORBs and arc basalts: Implications for oxygen fugacities of their mantle source regions. Geochimica et Cosmochimica Acta 69, A639-A639.

Lee, C.T.A., Yeung, L.Y., McKenzie, N.R., Yokoyama, Y., Ozaki, K., LENARDIC, A. (2016) Two-step rise of atmospheric oxygen linked to the growth of continents. Nature Geoscience 9, 417-+.

Magnabosco, C., Moore, K.R., Wolfe, J.M., Fournier, G.P. (2018) Dating phototrophic microbial lineages with reticulate gene histories. Geobiology 16, 179-189. 
Moussallam, Y., Oppenheimer, G., Scaillet, B. (2019) On the relationship between oxidation state and temperature of volcanic gas emissions. Earth and Planetary Science Letters 520, 260-267.

Nicklas, R.W., Puchte, I.S., Ash, R.D., Piccoli, H.M., Hanski, E., Nisbet, E.G., Waterton, P., Pearson, D.G., Anbar, A.D. (2019) Secular mantle oxidation across the Archean-Proterozoic boundary: Evidence from $\mathrm{V}$ partitioning in komatiites and picrites. Geochimica et Cosmochimica Acta 250, 49-75.

Nisbet, E.G., Cheadle, M.J., ARndt, N.T., Bickle, M.J. (1993) Constraining the Potential Temperature of the Archean Mantle - a Review of the Evidence from Komatiites. Lithos 30, 291-307.

Oppenheimer, C., Scaillet, B., Woods, A., Sutton, A.J., Elias, T., Moussallam, Y. (2018) Influence of eruptive style on volcanic gas emission chemistry and temperature. Nature Geoscience 11, 678-681.

Ostrander, C.M., Nielsen, S.G., Owens, J.D., Kendall, B., Gordon, G.W., Romaniello, S.J., ANBAR, A.D. (2019) Fully oxygenated water columns over continental shelves before the Great Oxidation Event. Nature Geoscience 12, 186-191.

PAVlov, A.A., Kasting, J.F. (2002) Mass-independent fractionation of sulfur isotopes in Archean sediments: Strong evidence for an anoxic Archean atmosphere. Astrobiology 2, 27-41.

Planavsky, N.J., Asael, D., Hofmann, A., Reinhard, C.T., Lalonde, S.V., Knudsen, A., Wang, X.L., Ossa, F.O., Pecoits, E., Smith, A.J.B., Beukes, N.J., Bekker, A., Johnson, T.M., Konhauser, K.O., LYONS, T.W., RouxEL, O.J. (2014) Evidence for oxygenic photosynthesis half a billiion years before the Great Oxidation Event. Nature Geoscience 7, 283-286.

SATKoski, A.M., Beukes, N.J., Li, W.Q., BeArd, B.L., Johnson, C.M (2015) A redox-stratified ocean 3.2 billion years ago. Earth and Planetary Science Letters 430, 43-53.

Schirrmeister, B.E., Gugger, M., Donoghue, P.C.J. (2015) Cyanobacteria and the Great Oxidation Event: evidence from genes and fossils. Palaeontology 58, 769-785.

SLEEP, N.H. (2005) Dioxygen over geological time. Biogeochemical Cycles of Elements 43, 49-73.

SLEEP, N.H. (2018) Geological and Geochemical Constraints on the Origin and Evolution of Life. Astrobiology 18, 1199-1219.

Zahnle, K., Claire, M., Catling, D. (2006) The loss of mass-independent fractionation in sulfur due to a Palaeoproterozoic collapse of atmospheric methane. Geobiology 4, 271-283. 